\title{
Molecularly Characterised Xenograft Tumour Mouse Models: Valuable Tools for Evaluation of New Therapeutic Strategies for Secondary Liver Cancers
}

\author{
Daniela Mischek, ${ }^{1,2}$ Ralf Steinborn, ${ }^{3,4}$ Helga Petznek, ${ }^{1}$ Christoph Bichler, ${ }^{5}$ Kurt Zatloukal, ${ }^{6}$ \\ Michael Stürzl, ${ }^{7}$ Walter H. Günzburg, ${ }^{1}$ and Christine Hohenadl ${ }^{1}$
}

${ }^{1}$ Department of Pathobiology, Institute of Virology, University of Veterinary Medicine, Veterinaerplatz 1, 1210 Vienna, Austria

${ }^{2}$ Department of Data collection, Statistics, and Risk assessment, Austrian Agency for Health and Food Safety (AGES), Spargelfeldstrasse 191, 1226 Vienna, Austria

${ }^{3}$ Department of Biomedical Sciences, Institute of Animal Breeding and Genetics, University of Veterinary Medicine, Veterinaerplatz 1, 1210 Vienna, Austria

${ }^{4}$ VetOMICS, University of Veterinary Medicine, Veterinaerplatz 1, 1210 Vienna, Austria

${ }^{5}$ Department of Surgery, Medical University Vienna, Währinger Gürtel 18-20, 1090 Vienna, Austria

${ }^{6}$ Department of Pathology, Medical University of Graz, Auenbruggerplatz 25, 8036 Graz, Austria

${ }^{7}$ Division of Molecular and Experimental Surgery, Department of Surgery, University of Erlangen-Nürnberg,

Schwabachanlage 10, 91054 Erlangen, Germany

Correspondence should be addressed to Christine Hohenadl, christine.hohenadl@vu-wien.ac.at

Received 10 July 2008; Revised 5 November 2008; Accepted 19 December 2008

Recommended by Lisa Wiesmuller

To develop and evaluate new therapeutic strategies for the treatment of human cancers, well-characterised preclinical model systems are a prerequisite. To this aim, we have established xenotransplantation mouse models and corresponding cell cultures from surgically obtained secondary human liver tumours. Established xenograft tumours were patho- and immunohistologically characterised, and expression levels of cancer-relevant genes were quantified in paired original and xenograft tumours and the derivative cell cultures applying RT-PCR-based array technology. Most of the characteristic morphological and immunohistochemical features of the original tumours were shown to be maintained. No differences were found concerning expression of genes involved in cell cycle regulation and oncogenesis. Interestingly, cytokine and matrix metalloproteinase encoding genes appeared to be expressed differentially. Thus, the established models are closely reflecting pathohistological and molecular characteristics of the selected human tumours and may therefore provide useful tools for preclinical analyses of new antitumour strategies in vivo.

Copyright (C) 2009 Daniela Mischek et al. This is an open access article distributed under the Creative Commons Attribution License, which permits unrestricted use, distribution, and reproduction in any medium, provided the original work is properly cited.

\section{Introduction}

The liver is a common site of distant metastasis originating from different neoplasms including gastrointestinal (pancreatic, stomach, colorectal), lung and breast cancers. Also primary liver tumours such as cholangiocellular carcinomas (CCC), cancers of the bile ducts [1], may disseminate into the liver. Surgical resection still is the most promising therapy of secondary liver tumours, however, only a minority of patients are candidates for resection, and no adjuvant treatment has been demonstrated to be effective in increasing the survival rate following radical surgery $[2,3]$. For unresectable disease, several treatments have been tested in the clinical setting; however, none of them can be currently considered a standard approach. This also applies to systemic chemotherapy, although newer regimens appear to at least improve median survival [4]. Locoregional therapies such as hepatic intra-arterial chemotherapy and isolated hepatic perfusion may be offered to patients with unresectable liver metastases in the absence of extrahepatic disease; however, 
the efficacy of these treatments is still being determined. Both systemic and locoregional chemotherapy might be useful in the neoadjuvant setting to increase the resectability of liver metastases initially not amenable to surgical resection.

Due to its poor prognosis and unsatisfying treatment options, suitable animal models for secondary liver cancer are required as a prerequisite for studying factors involved in the pathogenesis of the disease as well as for the development and evaluation of new anticancer therapies. Various approaches include the use of transgenic or knockout mice $[5,6]$ or mouse models, in which tumour formation is induced chemically [7]. Albeit tumours develop in all of these mouse models, tumour formation and progression in mice greatly differ from that in man $[8,9]$ due to physiological differences between the species and differences in cellular and molecular events contributing to cancer development. Tumour models established with primary human tumour tissue may overcome some of these limitations. To this aim, immune compromised animals, such as severe combined immunodeficient (SCID) mice, are grafted either subcutaneously or orthotopically with cultured cells $[10,11]$ or tissue derived from human tumour material [12-15] providing convenient models for evaluation of distinct anticancer strategies, especially those targeting tumour growth. Although discussions are ongoing arguing that the orthotopic transplantation model closer resembles the situation in the patient, subcutaneous xenografts still remain the standard for cancer drug screening in the pharmaceutical industry. In both cases, only detailed knowledge about the transplanted tumour cells will facilitate correct interpretation of gained results.

Thus, in the present study liver metastases derived from various human adenocarcinomas were used to establish subcutaneous xenograft tumours in SCID/beige mice. Extensive histological analyses were performed to demonstrate that the transplants widely reflect the characteristics of the parental lesion. In addition, gene expression profiling by means of RT-PCR-based microarrays revealed that expression of cancer-related genes appeared to be similar in corresponding original and xenograft tumours as well as in derived cell cultures. Therefore, we conclude that the established tumour models and cell cultures may represent valuable tools for the development and analysis of new treatments targeting secondary liver tumours.

\section{Materials and Methods}

2.1. Human Tumour Tissue. Primary and secondary liver tumours were obtained from patients at the time of liver transplantation or surgical resection of the neoplasm. Immediately after surgical resection, tumour samples were transferred into transport medium (RPMI 1640, SigmaAldrich, Wien, Austria) containing 10\% heat-inactivated foetal bovine serum (FBS) (PAA, Pasching, Austria), $100 \mathrm{U} / \mathrm{mL}$ penicillin-streptomycin (PAA), $2.5 \mu \mathrm{g} / \mathrm{mL}$ fungizone (Sigma), and $100 \mu \mathrm{g} / \mathrm{mL}$ gentamycin (Biochrom AG, Berlin, Germany). Tumour samples were kept on ice until processed further.
2.2. Establishment of Xenograft Tumour Models in SCID/Beige Mice. Human tumour samples with an average size of $1 \mathrm{~cm}^{3}$ were cut into $2 \times 2 \mathrm{~mm}$ pieces in the presence of digestion medium (PBS $/ 2 \mathrm{mg} / \mathrm{mL}$ collagenase III; $37^{\circ} \mathrm{C}$; Worthington Biochemical Corporation, NJ, USA), transferred into $15 \mathrm{~mL}$ tubes (Sarstedt, Wiener Neustadt, Austria) and further incubated for 1 hour at $37^{\circ} \mathrm{C}$ with continuous shaking at 320 cycles per minute (Thermoshaker HTMR 132; Haep Labor Consult, Bovenden, Germany). To stop digestion, an equal volume of culture medium (DMEM/10\% FBS/50 U/mL penicillin-streptomycin) was added. The obtained single cell suspension was centrifuged at $180 \mathrm{xg}$ for 5 minutes, and cells were washed twice with PBS. The cell pellet was resuspended in $1 \mathrm{~mL}$ of injection medium (RPMI 1640 phenol red free/1\% penicillin-streptomycin) and 150$200 \mu \mathrm{L}$ thereof were inoculated subcutaneously into the left flank of 3 SCID/beige mice (C.B-17/IcrHsd-Prkcd ${ }^{\text {scid }}$ Lyst ${ }^{\mathrm{bg}}$; Harlan-Winkelmann, Borchen, Germany) which had been anaesthetised by intraperitoneal injection of ketamine $(1 \mathrm{mg} / 10 \mathrm{~g}$ body weight $)$ and xylazin $(0.039 \mathrm{mg} / 10 \mathrm{~g}$ body weight). For individual identification, microchip transponders (BackHome; Virbac, Wien, Austria) were implanted subcutaneously. Animals were kept under specific pathogenfree conditions in negative pressure containments (Scantainers, Scanbur, Denmark) with unlimited access to food and autoclaved tap water. Subcutaneous tumour volume was estimated according to Carlsson's formula [16]. Hence, the largest (a) and smallest (b) superficial diameters of the tumour were determined once a week using a sliding calliper, and then the volume $(V)$ was calculated $(V=a \times b \times b / 2)$. At $300-500 \mathrm{~mm}^{3}$, tumours were excised and parts of them, that is, pieces of $2 \mathrm{~mm}^{3}$, transplanted into new animals, fixed in formalin or frozen in liquid nitrogen. All animal experiments were performed according to Austrian laws governing animal experimentation (GZ 68.205/30-Pr/4/2002; GZ 68.205/59BrGT/2004).

\subsection{Establishment and Characterisation of Primary and Xeno-} graft Tumour Derived Cell Cultures. Tumour pieces either obtained from primary (AKH23, KFJ18) or xenografted tumours (AKH10, KFJ6, KFJ9, KFJ10) were processed as described above, and obtained single cell suspensions were transferred into cell culture flasks (Sarstedt) containing culture medium. Established cell cultures were characterised by immunocytochemistry using antibodies reacting with human and mouse major histocompatibility complex (MHC) class I antigens. Briefly, cells were incubated with a R-phycoerythrin—conjugated mouse anti-human leukocyte antigen (HLA)-A,B,C (BD Pharmingen, Schwechat, Austria) or a fluorescein isothiocyanate (FITC) - conjugated mouse antimouse H-2Dd monoclonal antibody (Becton Dickinson, Heidelberg, Germany) for one hour at $4^{\circ} \mathrm{C}$ in the dark. Cells were washed twice, resuspended in PBS, and subjected to FACS analysis (FACScalibur, Becton Dickinson). In addition, cells were stained with an antibody directed against a human epithelial-specific antigen (ESA; Serotec, Düsseldorf, Germany) followed by detection with FITCconjugated polyclonal rabbit anti-mouse immunoglobulin 
(DakoCytomation, Glostrup, Denmark). After characterisation, cells usually with passage numbers $5-10$ were frozen in liquid nitrogen for long-term storage. On demand cells were thawed and expanded for further in vitro analysis or retransplantation into immunodeficient mice. Therefore, $1-5 \times 10^{6}$ cells were injected subcutaneously into SCID/beige mice as described above. In addition to tumour growth in vivo, anchorage independent growth of recultivated tumourderived cells was analysed by colony formation in a standard soft agar assay [17].

2.4. Histopathological Analysis and Immunohistochemistry. Xenograft tumours after the first or second passage in mice were excised and fixed in $4 \%$ buffered formalin (pH 7.0, Sigma-Aldrich) and embedded in paraffin (HistoComp, Sanova, Wien, Austria) using automatic embedding equipment (Tissue Tek, Miles Scientific, Inc., Ill, USA). Three $\mu \mathrm{m}$ thick sections of primary and xenograft tumours were routinely stained with haematoxylin and eosin and microscopically analysed. To characterise primary tumours and corresponding xenografts by immunohistochemistry, the following primary antibodies were used: rabbit polyclonal antibody specific for carcinoembryonic antigen (CEA, CD66e Ab-2, neat, Labvision Neomarkers, Cheshire, UK), mouse monoclonal antibodies specific for cytokeratin $8 / 18$ (CK8/18 Labvision Neomarkers, 1:100 diluted in PBS) and cytokeratin 20 (CK20, DakoCytomation; 1:50 diluted in PBS). For detection of CK8/18, sections were digested with $0.1 \%$ protease (Sigma-Aldrich) in PBS for 15 minutes. CK20 was detected after pretreatment with $0.1 \%$ proteinase $K$ (Sigma-Aldrich) in PBS. Sections were then incubated with $1.5 \%$ goat serum (DakoCytomation) for 30 minutes followed by overnight incubation with the primary antibody at $4^{\circ} \mathrm{C}$. Detection was performed using the Vectastain ABC-AP kit (Vector Laboratories, England, UK) with New Fuchsin (DakoCytomation) as a substrate followed by counterstaining with Mayer's haemalum (VWR International $\mathrm{GmbH}$, Dresden, Germany). Sections were covered with Aquatex (Merck, Darmstadt, Germany) and examined by light microscopy (Zeiss Axiovert $200 \mathrm{M}$, Carl Zeiss GmbH, Oberkochen, Germany).

2.5. RNA Extraction, Reverse Transcription, and Quantitative $R T-P C R$. RNA was extracted from trypsinised cells or frozen and pulverised tumour samples according to the RNeasy Mini Kit protocol (Qiagen, Wien, Austria) and treated afterwards with Turbo DNase (Ambion, Tex, USA) according to the manufacturer's instructions. Subsequently, $150 \mathrm{ng}$ of total RNA were reverse transcribed using the iScript cDNA synthesis Kit (Bio-Rad Laboratories, Calif, USA). $50 \mu \mathrm{L}$ of cDNA template (105 ng total input RNA) were amplified using a master mix containing $1 \mathrm{x}$ reaction buffer $\mathrm{B}$ (Solis Biodyne, Tartu, Estonia), $5 \mathrm{mM} \mathrm{MgCl}, 0.2 \mathrm{mM}$ of each dNTP (Applied Biosystems, Calif, USA), 300 nM ROX reference dye (Invitrogen, Lofer, Germany) and 1 unit of hot start Firepol polymerase (Solis Biodyne, Tartu, Estonia) on TaqMan low density arrays (Applied Biosystems) using the ABI PRISM 7900HT sequence detection system (Applied
Biosystems). The respective human-specific real-time PCR primers and probes are listed in Table 1. According to data base comparisons (Applied Biosystems), these sequences are not supposed to cross-react with mouse. Cycling conditions were as follows: 2 minutes at $50^{\circ} \mathrm{C}, 10$ minutes at 94.5 followed by 40 cycles of 30 seconds at $97^{\circ} \mathrm{C}$ and 1 minute at $59.7^{\circ} \mathrm{C}$. Ct values were determined using the passive reference dye and manual baseline and threshold settings in the SDS 2.2 software (Applied Biosystems). Assays with Ct values above 33 were excluded from analysis due to variations or inappropriate amplification in duplicate wells. Tumour-derived RNA was tested in duplicates on three different plates, and their mean values were calculated for further analysis. A calibrator sample consisting of a universal reference RNA isolated from 10 different human cancer cell lines (Stratagene, Calif, USA) served as an internal standard for comparison of different assays. Differences in gene expression levels of each tumour sample were first normalised to the calibrator sample followed by calculation of differences between original and xenograft tumours according to the $2^{-\Delta \Delta \mathrm{Ct}}$ method [18]. Normalisation of real-time RT-PCR data was performed using the geometric mean (normalisation factor) of the included endogenous reference genes GUSB (B-glucuronidase), ACTB (B-actin) and rRNA18S (18S ribosomal RNA) within the macrosbased program qBase (http://medgen.ugent.be/qbase).

2.6. Statistical Analysis. To identify genes expressed differentially in all xenografts and parental tumours analysed, a Wilcoxon paired-samples test was performed (SPSS for Windows Vs. 11.5). Statistical significance was defined as $P<.05$. For the analysis of individual original/xenograft tumour pairs, we considered genes to be differentially expressed showing a minimum of 2.5 -fold difference between xenograft and original tumours.

\section{Results}

3.1. Successful Establishment of Secondary Liver Tumour Models in SCID/Bg Mice. Human secondary liver tumour tissue was obtained from patients at the time of surgery or resection of the neoplasm. In total, tumour samples from 17 patients including liver metastases of colorectal carcinomas $(n=10)$, intrahepatic cholangiocellular carcinomas $(n=$ 6) as well as a metastasis of a pancreatic carcinoma were collected. The tumour tissue was digested with collagenase to obtain single cell suspensions which were injected subcutaneously into SCID/beige mice. Finally, injection of single cells prepared from 10 different samples consisting of liver metastases originating from colorectal $(n=6)$, cholangiocellular $(n=3)$, and a pancreatic adenocarcinoma resulted in tumour formation. The main characteristics of the original xenografted tumour samples are summarised in Table 2.

\subsection{Histopathological Features of Original Human Tumours Are Conserved in Corresponding Xenografts. In order to compare original and xenograft tumours morphologically,}




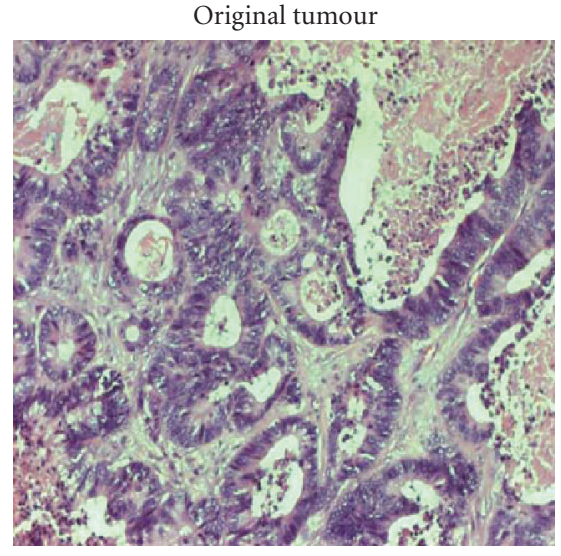

(a)

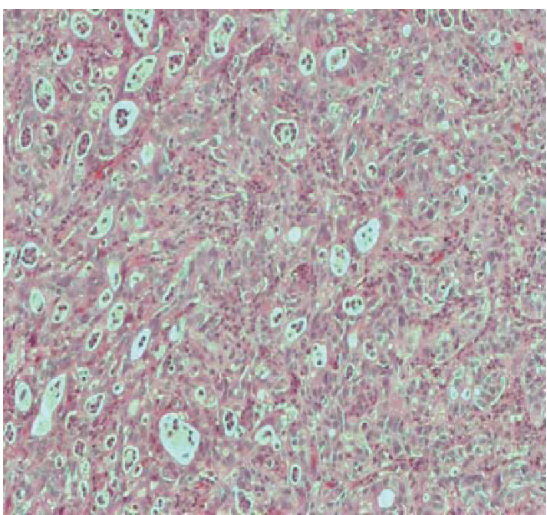

(c)

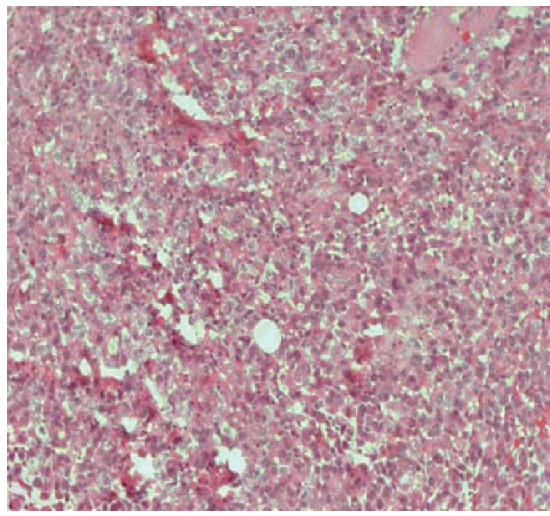

(e)

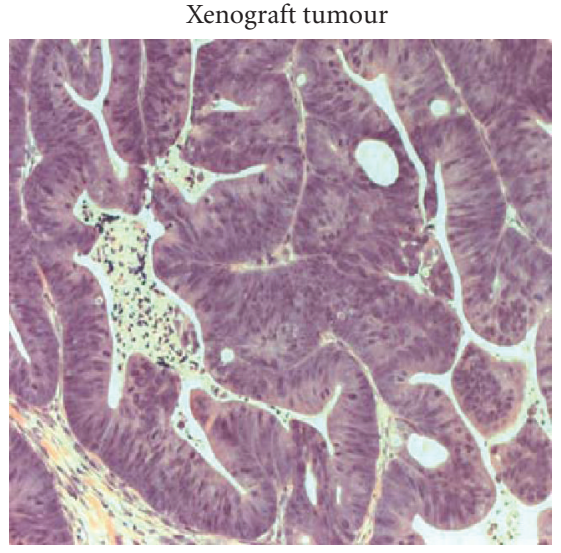

(b)

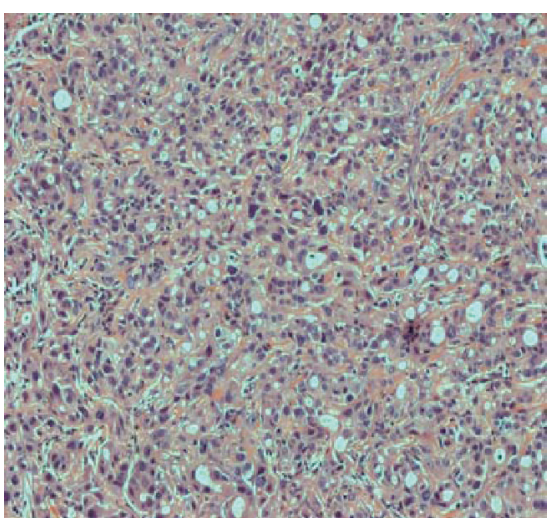

(d)

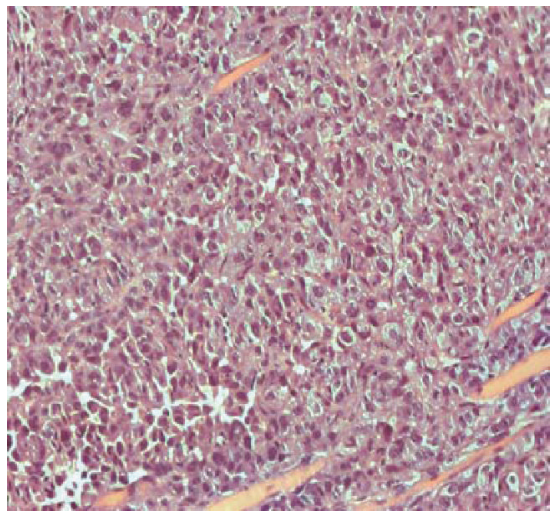

(f)

FIGURE 1: Histological analysis of original and corresponding xenograft tumours. (a) KFJ6 (colorectal liver metastasis) original tumour, (b) KFJ6-derived xenograft tumour, (c) AKH10 (cholangiocellular carcinoma) original tumour, (d) AKH10-derived xenograft tumour, (e) AKH23 (pancreatic adenocarcinoma-derived liver metastasis) original tumour, (f) AKH23-derived xenograft tumour. Sections were stained with haematoxylin and eosin. Magnification: 200x.

sections were stained with haematoxylin/eosin and examined by light microscopy. Representatively for colorectal liver metastases, sections of the original tumour KFJ6 and its derived xenograft are shown (see Figures 1(a) and 1(b)). Both original as well as the xenograft tumours revealed irregular tubular structures typical for colon adenocarcinomas. In most of the established xenograft tumours, large areas of necrosis were observed (data not shown). The tumour AKH10 is depicted as an example of an intrahepatic cholangiocellular carcinoma (see Figures 1(c) and 1(d)). Pathohistologically, both xenograft and the parental tumour can be described as a moderately differentiated adenocarcinoma with comparable simple tubular to glandular structures. Examination of the liver metastasis AKH23 which 
TABLE 1: Sequences amplified on TaqMan low density arrays.

\begin{tabular}{|c|c|c|c|}
\hline Gene & Gene name & Classification & TaqMan assay ID $^{\mathrm{a}}$ \\
\hline BCL2 & B-cell CLL/lymphoma 2 & Inhibition of apoptosis & Hs00153350_m1 \\
\hline CCND1 & Cyclin D1 & Kinase activator, cell cycle control, proliferation & Hs00277039_m1 \\
\hline CDC25B & Cell division cycle 25B & Protein phosphatase, cell proliferation & Hs00244740_m1 \\
\hline CDKN1B & $\begin{array}{l}\text { Cyclin-dependent kinase inhibitor 1B (p27, } \\
\text { Kip1) }\end{array}$ & Cell cycle control, tumour suppressor & Hs00153277_m1 \\
\hline CTNNB1 & $\begin{array}{l}\text { Catenin (cadherin-associated protein), beta } 1 \text {, } \\
88 \mathrm{kDa}\end{array}$ & Cytoskeletal protein, cell adhesion, oncogenesis & Hs00170025_m1 \\
\hline EGFR & $\begin{array}{l}\text { Epidermal growth factor receptor } \\
\text { (erythroblastic leukemia viral (v-erb-b) } \\
\text { oncogene homolog) }\end{array}$ & Cell cycle control, proliferation, oncogenesis & Hs00193306_m1 \\
\hline ERBB2 & $\begin{array}{l}\text { v-erb-b2 erythroblastic leukemia viral } \\
\text { oncogene homolog } 2\end{array}$ & $\begin{array}{l}\text { Protein kinase receptor, oncogenesis, cell cycle } \\
\text { control }\end{array}$ & Hs00170433_m1 \\
\hline ETV4 & $\begin{array}{l}\text { ets variant gene } 4 \text { (E1A enhancer binding } \\
\text { protein, E1AF) }\end{array}$ & Transcription factor, oncogenesis, cell motility & Hs00385910_m1 \\
\hline IL6 & Interleukin 6 (interferon, beta 2) & Chemokine, inhibition of apoptosis & Hs00174131_m1 \\
\hline IL6R & Interleukin 6 receptor & Cell proliferation, immunity and defense & Hs00169842_m1 \\
\hline IL8 & Interleukin 8 & Angiogenesis, cell proliferation/differentiation & Hs00174103_m1 \\
\hline KRAS & $\begin{array}{l}\text { v-Ki-ras2 Kirsten rat sarcoma } 2 \text { viral oncogene } \\
\text { homolog }\end{array}$ & Small GTPase, cell proliferation/differentiation & Hs00270666_m1 \\
\hline MET & $\begin{array}{l}\text { Met proto-oncogene (hepatocyte growth factor } \\
\text { receptor) }\end{array}$ & Protein kinase receptor, oncogenesis & Hs00179845_m1 \\
\hline MMP1 & $\begin{array}{l}\text { Matrix metalloproteinase } 1 \text { (interstitial } \\
\text { collagenase) }\end{array}$ & $\begin{array}{l}\text { Metalloprotease, extracellular matrix break } \\
\text { down }\end{array}$ & Hs00233958_m1 \\
\hline MMP11 & Matrix metalloproteinase 11 (stromelysin 3) & Metalloprotease, inhibition of apoptosis & Hs00171829_m1 \\
\hline MYC & $\begin{array}{l}\text { v-myc myelocytomatosis viral oncogene } \\
\text { homolog }\end{array}$ & Oncogene, cell cycle control & Hs00153408_m1 \\
\hline PTGS2 & $\begin{array}{l}\text { Prostaglandin-endoperoxide synthase } 2 \\
\text { (prostaglandin G/H synthase and } \\
\text { cyclooxygenase, Cox-2) }\end{array}$ & $\begin{array}{l}\text { Oxidoreductase, lipid metabolism, deregulated } \\
\text { in epithelial tumours }\end{array}$ & Hs00153133_m1 \\
\hline SERPINB5 & $\begin{array}{l}\text { Serine proteinase inhibitor, clade B } \\
\text { (ovalbumin), member } 5\end{array}$ & Proteinase inhibitor, oncogenesis & Hs00184728_m1 \\
\hline VEGFA & Vascular endothelial growth factor & Growth factor, angiogenesis & Hs00173626_m1 \\
\hline VEGFC & Vascular endothelial growth factor C & Cell proliferation and differentiation & Hs00153458_m1 \\
\hline WNT1 & $\begin{array}{l}\text { Wingless-type MMTV integration site family, } \\
\text { member } 1\end{array}$ & Signalling molecule, oncogenesis & Hs00180529_m1 \\
\hline rRNA18S & $18 \mathrm{~S}$ ribosomal RNA & $\begin{array}{l}\text { Eukaryotic ribosomal RNA gene, obligatory } \\
\text { control }\end{array}$ & $4342379-18 S$ \\
\hline GUSB $^{b}$ & Glucuronidase, beta & Galactosidase, carbohydrate metabolism & Hs99999908_m1 \\
\hline $\mathrm{ACTB}^{\mathrm{b}}$ & Actin, beta & Cytoskeletal protein & Hs99999903_m1 \\
\hline
\end{tabular}

had originated from a pancreatic adenocarcinoma revealed a solid undifferentiated large cell carcinoma (see Figure 1(e)). Tumour cells exhibited anaplastic nuclei and varying amounts of eosinophilic, particular foamy cytoplasm. Consistently, subcutaneous implantation of cells derived from tumour AKH23 led to formation of a poorly differentiated fast growing anaplastic carcinoma (see Figure 1(f)).

3.3. Typical Tumour Markers Are Equally Expressed in Corresponding Tumour Samples. To further characterise the established xenograft tumours and their corresponding original counterparts, immunohistological stainings for detection of CEA were performed. CEA is a glycoprotein expressed in adenocarcinomas of the intestinal tract and in other tumours of epithelial origin such as lung adenocarcinoma, pancreatic adenocarcinoma, and cholangiocellular carcinomas (CCCs) [19]. Additionally, tumours were stained with antibodies specific for CK8/18, which is expressed in simple and glandular epithelia, and CK20, which is primarily expressed in colon adenocarcinomas. Pancreatic tumours and CCCs may also express CK20 [20]. As summarised in Table 3, immunohistological analyses revealed similar staining patterns within 
TABLE 2: Relevant characteristics of original human tumour samples.

\begin{tabular}{lccc}
\hline Tumour ID & Age & Sex & Diagnosis $^{\mathrm{a}}$ \\
\hline AKH10 & 72 & $\mathrm{~m}$ & Intrahepatic multifocal CCC \\
AKH23 & 65 & $\mathrm{f}$ & Intrahepatic CCC \\
AKH47 & 63 & $\mathrm{~m}$ & Pancreatic adenocarcinoma derived liver metastasis \\
KFJ6 & 75 & $\mathrm{~m}$ & CRC derived liver metastasis \\
KFJ9 & 55 & $\mathrm{f}$ & Intrahepatic metastatic CCC \\
KFJ10 & 65 & $\mathrm{~m}$ & CRC derived liver metastasis \\
KFJ12 & 78 & $\mathrm{f}$ & CRC derived liver metastasis \\
KFJ18 & 64 & $\mathrm{~m}$ & CRC derived liver metastasis \\
KFJ21 & 52 & $\mathrm{~m}$ & CRC derived liver metastasis \\
KFJ25 & 73 & & CRC derived liver metastasis \\
\hline
\end{tabular}

${ }^{a}$ CCC: cholangiocellular carcinoma; CRC: colorectal carcinoma.

original and xenograft tumour samples with regard to expression of CEA, CK8/18, and CK20. Positive staining exclusively detected in distinct original tumour samples was due to reactions with normal liver cells no more present in the xenograft tumours. Representative analyses of original tumours and their corresponding xenografts are shown in Figures 2-4. Immunohistological comparison of the original and xenograft tumour KFJ6 in both samples revealed expression of CEA in the cytoplasm and membranes of luminal cells (see Figures 2(a) and 2(b)). Additionally, expression of CK8/18 (see Figures 2(c) and 2(d)) and CK20 (see Figures 2(e) and 2(f)) was detected. AKH10 original and xenograft tumours (see Figure 3 ) both reacted with antibodies specific for CEA (see Figures 3(a) and 3(b)) and CK8/18 (see Figures 3(c) and 3(d)) but did not show expression of CK20 (see Figures 3(e) and 3(f)). The original pancreatic adenocarcinoma-derived liver metastasis AKH23 (see Figure 4) revealed single cells expressing CEA (see Figure 4(a)), whereas the corresponding xenograft tumour appeared negative for CEA expression. A robust staining in both samples was obtained when expression of CK8/18 (see Figures 4(c) and 4(d)) was analysed. In contrast, neither original nor xenograft tumour-derived sections revealed expression of CK20 (see Figures 4(e) and 4(f)). Based on these findings, we conclude that the investigated human tumours retained their typical morphological and histological characteristics after xenotransplantation into mice.

3.4. Expression of Cancer Relevant Genes Appears Unaltered in Xenograft Compared to Original Tumours. In order to compare the established xenograft tumour models with the respective original tumour counterparts on a molecular basis, gene expression analyses were performed. For this purpose, relative expression levels of a number of cancerrelevant genes (see Table 1) were determined in the respective corresponding tumour samples using TaqMan low density expression arrays. Interassay specific differences were first normalised to an arbitrarily chosen calibrator (reference RNA), and then the ratio of gene expression levels in an original tumour versus the corresponding xenograft tumour was determined. Genes were considered to be differentially expressed when a 2.5-fold minimal difference between original and xenograft tumour samples was obtained. Table 4 summarises data acquired for a representative selection of different original tumours in comparison to their respective xenografts. Interestingly, genes encoding cell cycle regulators and proto-oncogenes, such as Bcl-2, cyclin D1, CDC25B, cyclin-dependent kinase inhibitor 1B, Erb-b2, K-ras, Met and $\mathrm{Myc}$ as well as epidermal growth factor receptor (EGFR) and a B-catenin encoding gene (CTNNB1), showed comparable expression levels in all the investigated original and xenograft tumours. Expression of the proto-oncogene Wnt-1 was neither detected in original nor in xenograft tumour tissue. In contrast, genes encoding cytokines such as interleukin 8 (IL-8) and 6 (IL-6), its receptor IL6-R, cyclooxygenase (Cox)-2, vascular endothelial growth factor (VEGF)-C as well as matrix metalloproteinase (MMP) 11 appeared to be differentially expressed in some of the analysed samples (see Table 4). In particular, IL-6, Cox-2, and VEGF-C expression was nearly exclusively detected in original tumour samples. Expression of IL-6 receptor (IL$6 \mathrm{R}$ ) was either found to be equal in original and xenograft tumours or significantly increased (4- to 18-fold) in some of the original tumours (AKH10, KFJ18, KFJ21). Similarly, IL8 appeared to be 12 - to 100 -fold higher expressed in original tumour samples compared to the corresponding xenograft tissue. Analysis of MMP-11 expression revealed a 4- to 22fold difference between original and xenograft tumours. Although few more differences were encountered concerning expression of serpin and VEGF (AKH23), statistical analysis of results obtained for all investigated original and xenograft tumour samples revealed significant differences exclusively for the expression of IL-8 $(P=.017)$ and MMP-11 $(P=.018)$.

Finally, gene expression levels of original and xenograft tumour samples exemplarily were compared to those of their derived cell cultures (see Table 5). Immunocytochemical characterisation of established cell cultures confirmed their human and epithelial origin, respectively (data not shown). Again, the most striking differences in expression levels were observed for IL6-R and MMP encoding genes. IL6R-expression levels were about 5-fold decreased in tumour-derived cell cultures compared to the corresponding tissue. Demonstrative differences in MMP-1 expression were observed for AKH23-derived cells, which showed 
TABLE 3: Immunohistochemical analyses of human original and corresponding xenograft tumours. CCC: cholangiocellular carcinoma; CRC:

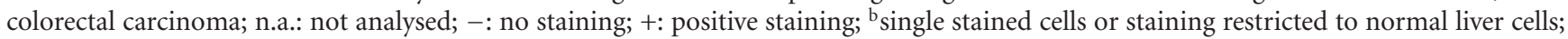
orig.: original tumour sample; xeno.: xenograft tumour sample.

\begin{tabular}{|c|c|c|c|c|}
\hline Tumour & Diagnosis & CEA orig./xeno. & CK8/18 orig./xeno. & CK20 orig./xeno. \\
\hline AKH10 & Intrahepatic metastatic CCC & $+/+$ & $+/+$ & $-1-$ \\
\hline AKH23 & Liver metastasis of pancreatic cancer & $+\mathrm{b} /-$ & $+/+$ & $-1-$ \\
\hline AKH47 & Intrahepatic CCC & $+\mathrm{b} /-$ & $+/+$ & $-1-$ \\
\hline KFJ6 & CRC liver metastasis & $+/+$ & $+/+$ & $+/+$ \\
\hline KFJ9 & Intrahepatic metastatic CCC & $+/+$ & $+/+$ & $+/+$ \\
\hline KFJ10 & CRC liver metastasis & $+/+$ & $+/+$ & $+/+$ \\
\hline KFJ12 & CRC liver metastasis & $+/+$ & $+/+$ & $+/+$ \\
\hline KFJ18 & CRC liver metastasis & $+/+$ & $+/+$ & $+/+$ \\
\hline KFJ21 & CRC liver metastasis & $+/+$ & $+/+$ & $+/+$ \\
\hline KFJ25 & CRC liver metastasis & $+/+$ & $+/+$ & $+/+$ \\
\hline
\end{tabular}

TABLE 4: Relative differences in gene expression levels (n-fold) of original tumour samples compared to the corresponding xenograft tumour. Indicated values represent the mean of three measurements including the calculated standard deviation. Ratios were calculated after normalisation of individual RNA amounts to a standard reference RNA. Values indicating differences higher than 2.5-fold are printed in bold. Gene symbols correspond with Table 1. n.d.: not determinable, Ct values obtained with cDNA derived either from the xenograft (\#) or from both tumour samples were below threshold $(>39)$.

\begin{tabular}{|c|c|c|c|c|c|c|c|c|}
\hline & AKH10 & AKH23 & KFJ6 & KFJ9 & KFJ10 & KFJ12 & KFJ18 & KFJ21 \\
\hline BCL2 & $0.35 \pm 0.06$ & $1.97 \pm 0.46$ & $1.66 \pm 0.72$ & $0.37 \pm 0.09$ & $0.80 \pm 0.20$ & $0.71 \pm 0.08$ & $1.10 \pm 0.26$ & $0.52 \pm 0.03$ \\
\hline CCND1 & $0.53 \pm 0.02$ & $1.91 \pm 0.25$ & $1.05 \pm 0.09$ & $0.94 \pm 0.22$ & $0.79 \pm 0.04$ & $1.96 \pm 0.09$ & $0.64 \pm 0.05$ & $0.74 \pm 0.15$ \\
\hline CDC25B & $1.79 \pm 0.31$ & $2.70 \pm 0.44$ & $0.45 \pm 0.02$ & $0.51 \pm 0.04$ & $1.05 \pm 0.11$ & $0.66 \pm 0.12$ & $0.60 \pm 0.01$ & $0.68 \pm 0.12$ \\
\hline CDKN1B & $1.93 \pm 0.65$ & $1.01 \pm 0.08$ & $0.85 \pm 0.07$ & $1.47 \pm 0.12$ & $2.03 \pm 0.32$ & $0.82 \pm 0.13$ & $0.66 \pm 0.16$ & $0.94 \pm 0.14$ \\
\hline CTNNB1 & $2.08 \pm 0.91$ & $1.20 \pm 0.24$ & $0.85 \pm 0.11$ & $1.75 \pm 0.02$ & $1.38 \pm 0.11$ & $0.82 \pm 0.23$ & $0.86 \pm 0.19$ & $0.86 \pm 0.15$ \\
\hline EGFR & $0.72 \pm 0.2$ & $1.05 \pm 0.1$ & $0.75 \pm 0.08$ & $0.75 \pm 0.08$ & $1.01 \pm 0.12$ & $0.64 \pm 0.12$ & $1.02 \pm 0.17$ & $1.00 \pm 0.22$ \\
\hline ERBB2 & $0.97 \pm 0.21$ & $1.43 \pm 0.15$ & $0.88 \pm 0.05$ & $1.04 \pm 0.03$ & $0.82 \pm 0.16$ & $0.74 \pm 0.08$ & $0.58 \pm 0.02$ & $1.21 \pm 0.46$ \\
\hline ETV4 & $1.79 \pm 0.17$ & $1.41 \pm 0.27$ & $0.67 \pm 0.05$ & $0.92 \pm 0.11$ & $1.02 \pm 0.11$ & $0.45 \pm 0.14$ & $0.49 \pm 0.12$ & $0.98 \pm 0.13$ \\
\hline IL6 & $1.69 \pm 0.55$ & $0.26 \pm 0.04$ & n.d.\# & $0.30 \pm 0.04$ & n.d.\# & n.d.\# & n.d.\# & n.d.\# \\
\hline IL6R & $4.86 \pm 1.35$ & $0.99 \pm 0.09$ & n.d.\# & $0.75 \pm 0.05$ & $1.75 \pm 0.14$ & $0.73 \pm 0.12$ & $18.33 \pm 1.98$ & $4.41 \pm 0.3$ \\
\hline IL8 & $1.06 \pm 0.28$ & $2.65 \pm 1.0$ & $18.46 \pm 5.67$ & $12.81 \pm 3.43$ & $23.46 \pm 6.74$ & $19.39 \pm 4.43$ & $34.84 \pm 3.42$ & $112.68 \pm 23.33$ \\
\hline KRAS2 & $0.97 \pm 0.23$ & $1.13 \pm 0.14$ & $0.81 \pm 0.14$ & $0.85 \pm 0.10$ & $1.62 \pm 0.37$ & $0.78 \pm 0.06$ & $0.87 \pm 0.10$ & $0.79 \pm 0.18$ \\
\hline MET & $0.58 \pm 0.14$ & $1.61 \pm 0.25$ & $0.57 \pm 0.08$ & $2.35 \pm 0.16$ & $0.95 \pm 0.04$ & $0.69 \pm 0.01$ & $0.58 \pm 0.10$ & $0.81 \pm 0.14$ \\
\hline MMP1 & $0.65 \pm 0.08$ & n.d.\# & $0.97 \pm 0.38$ & n.d. & $0.57 \pm 0.36$ & n.d. & $0.95 \pm 0.13$ & n.d.\# \\
\hline MMP11 & $15.62 \pm 6.10$ & $22.13 \pm 5.08$ & $5.66 \pm 0.21$ & n.d.\# & $8.33 \pm 1.68$ & $3.98 \pm 1.24$ & $13.72 \pm 2.43$ & $10.88 \pm 0.42$ \\
\hline MYC & $0.60 \pm 0.08$ & $1.60 \pm 0.46$ & $0.89 \pm 0.11$ & $0.89 \pm 0.18$ & $0.90 \pm 0.03$ & $0.86 \pm 0.25$ & $0.66 \pm 0.03$ & $0.97 \pm 0.05$ \\
\hline PTGS2 & $0.83 \pm 0.18$ & $0.43 \pm 0.07$ & n.d.\# & n.d.\# & n.d.\# & n.d.\# & n.d.\# & n.d.\# \\
\hline SERPINB5 & n.d. & $17.66 \pm 4.92$ & $1.11 \pm 0.15$ & $1.26 \pm 0.10$ & $0.58 \pm 0.18$ & $1.12 \pm 0.36$ & $0.38 \pm 0.05$ & $1.46 \pm 0.08$ \\
\hline VEGFA & $1.48 \pm 0.23$ & $0.17 \pm 0.01$ & $1.09 \pm 0.04$ & $2.78 \pm 0.32$ & $2.11 \pm 0.23$ & $0.94 \pm 0.12$ & $0.91 \pm 0.08$ & $1.38 \pm 0.22$ \\
\hline VEGFC & $1.52 \pm 0.32$ & n.d.\# & n.d.\# & n.d.\# & n.d.\# & n.d.\# & n.d.\# & n.d.\# \\
\hline WNT1 & n.d. & n.d. & n.d. & n.d. & n.d. & n.d. & n.d. & n.d. \\
\hline
\end{tabular}

a $>300$-fold higher amount of mRNA compared to the parental tumour. In contrast, MMP-11 (10-fold) and VEGF (4-fold) expression levels were found to be higher in AKH23 original tumour tissue.

\section{Discussion}

Tumour mouse models as well as tumour-derived cell lines are a prerequisite for the development and evaluation of new and existing tumour therapies. Although a number of xenograft models have been published for colorectal carcinomas and pancreatic adenocarcinomas in most cases, these were established from cultured cell lines available for example from ATCC. In these examples, it is not clear how long-term cultivation of these (mostly poorly characterised) cells affects tumour formation and biology. Therefore, we decided to establish xenografts directly from patient tumours and subsequently analyse both tissues in detail to demonstrate that the generated model closely reflects the original 


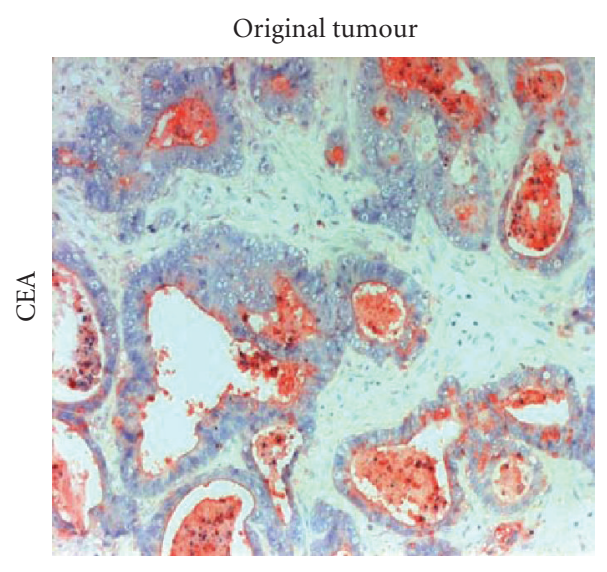

(a)

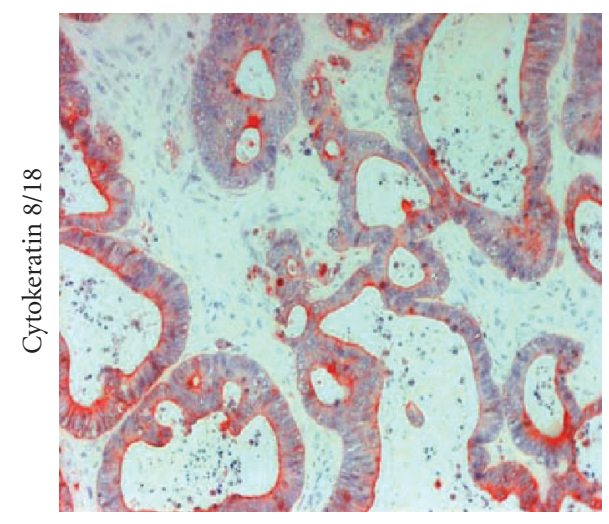

(c)

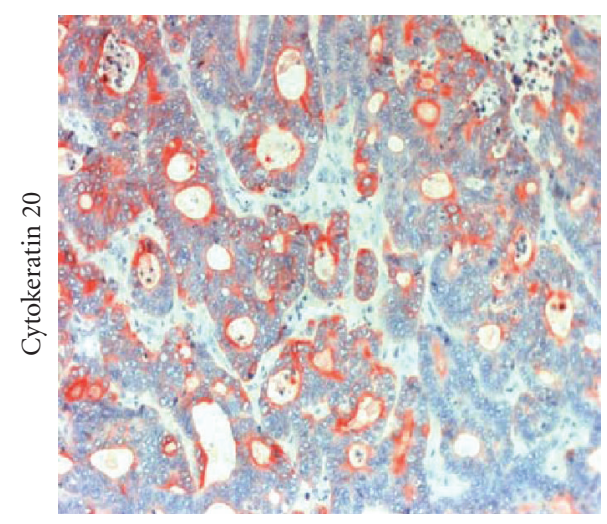

(e)

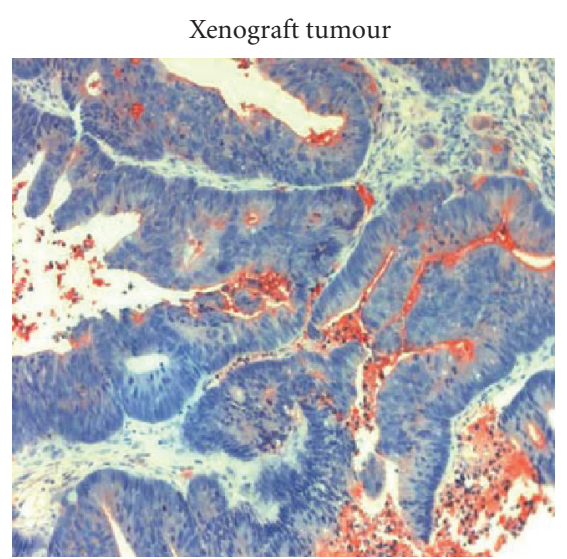

(b)

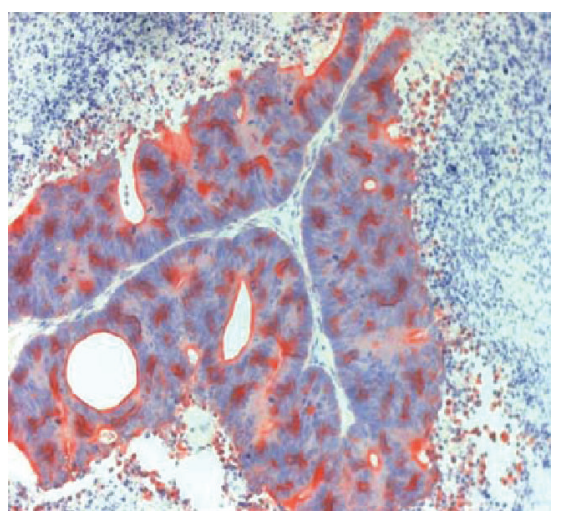

(d)

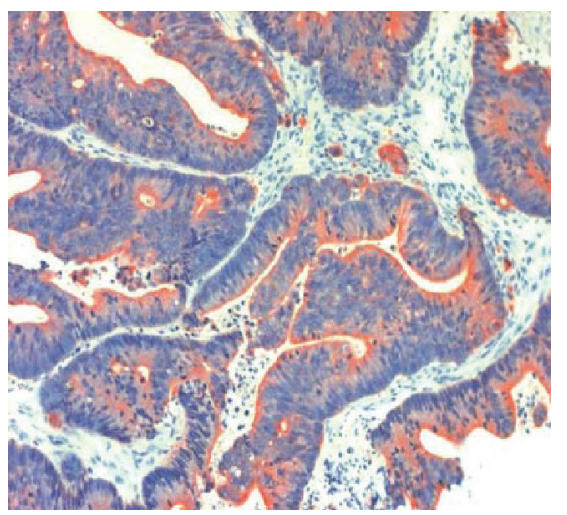

(f)

FIgURE 2: Immunohistochemical analysis of original and corresponding xenograft tumour KFJ6. Sections were stained with (a), (b) antibodies specific for CEA, (c), (d) cytokeratin 8/18, and (e), (f) cytokeratin 20. Magnification: 200x.

malignancy. In the present study, we report the establishment and detailed characterisation of human xenograft tumour models derived from secondary liver cancer, that is, tumour metastases originating from colorectal, cholangiocellular, and pancreatic cancers. Xenografts were established directly from tumour biopsies omitting culturing of isolated cells, which may cause development of tumours that do not share the characteristics of the respective original due to the selection and expansion of specific cell clones. The applied method of enzymatic digestion of whole tumour samples followed by injection of a mixture of tumour and stromal cells was shown to overcome this obstacle. With respect to xenografts derived from colorectal carcinomas, the applied method resulted in a take rate of $60 \%$ and $50 \%$, respectively, when cholangiocellular carcinoma-derived cells were injected. Retrospective analysis of xenograft tumour growth with clinical data of the respective patient did not reveal any significant correlation. Instead, the condition of 


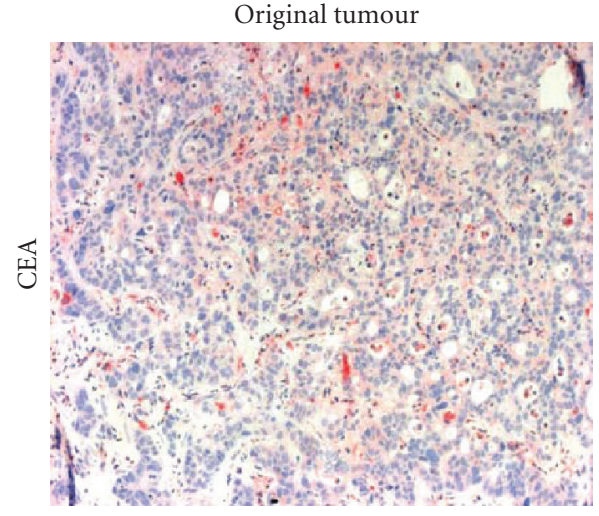

(a)

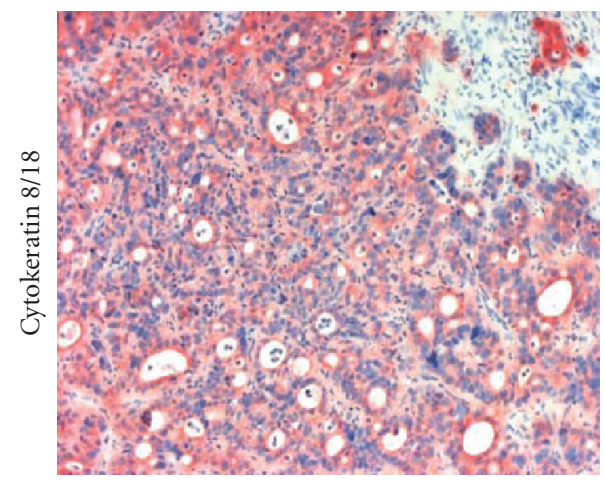

(c)

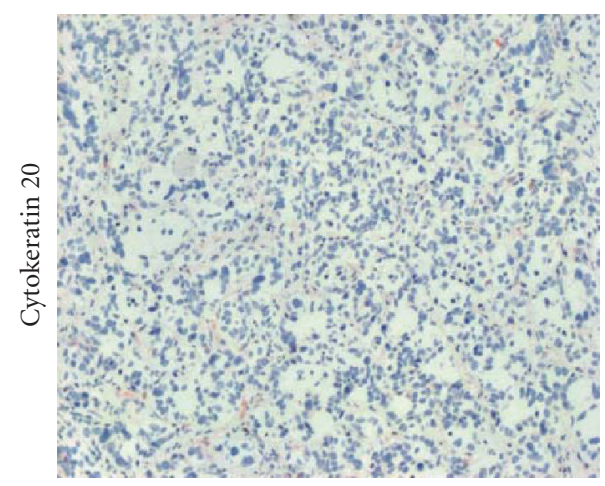

(e)

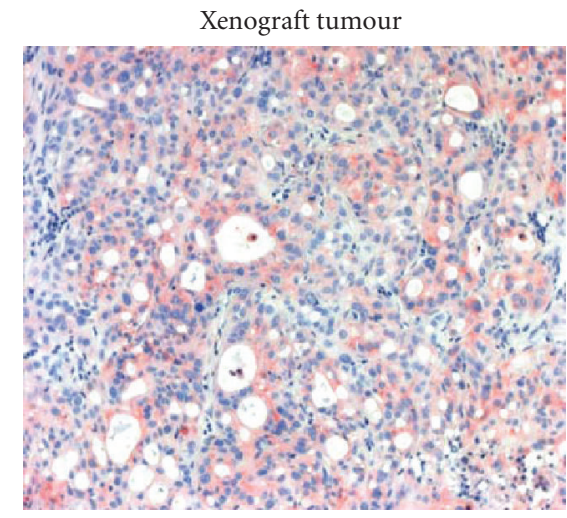

(b)

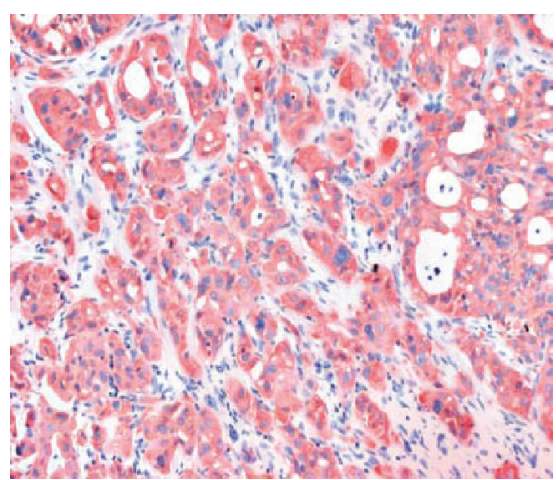

(d)

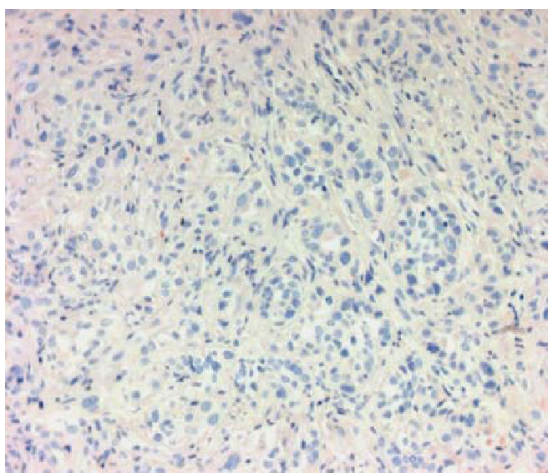

(f)

FIGURE 3: Immunohistochemical analysis of original and corresponding xenograft tumour AKH10. Sections were stained with (a), (b) antibodies specific for CEA, (c), (d) cytokeratin 8/18, and (e), (f) cytokeratin 20. Magnification: 200x.

the primary tumour sample, for example, the presence of large necrotic areas appeared to be critical.

Pathohistological examination of the established xenografts and comparison to their respective original tumours demonstrated that the typical morphology of the tumours was retained after xenotransplantation. Moreover, immunohistological analyses showed that each of the established xenograft tumours retained the typical tumour-specific antigen profile observed in the original tumour sample. Cell cultures established either from original or xenograft tumour tissues were shown to be of epithelial origin and not contaminated with murine cells (data not shown). Although the respective tumour transplants could be passaged in mice for extended periods (up to 30 times) without major changes in growth behaviour and morphology (data not shown), a cryoconservation protocol was established facilitating storage of samples at early passages to avoid development of histopathological alterations over time. Retransplantation experiments with tumour samples frozen for different time spans (3, 6, and 12 months) revealed an average take rate of $70 \%$ to $100 \%$ in both SCID/beige and nude mice.

Molecular characterisation based on quantitative gene expression analyses using human specific primers and probes 


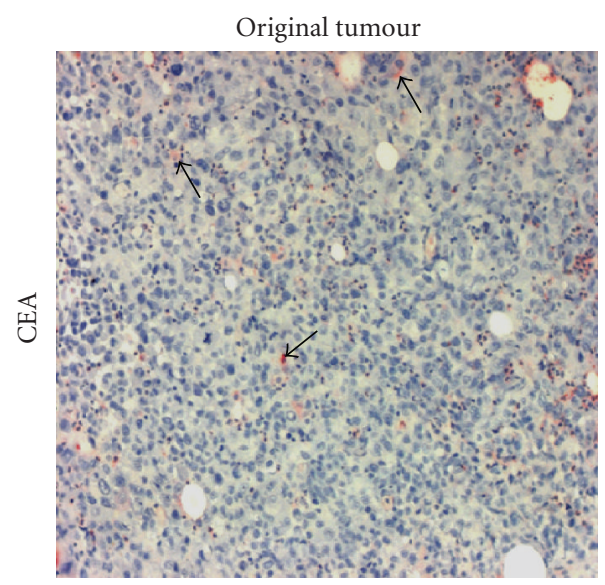

(a)

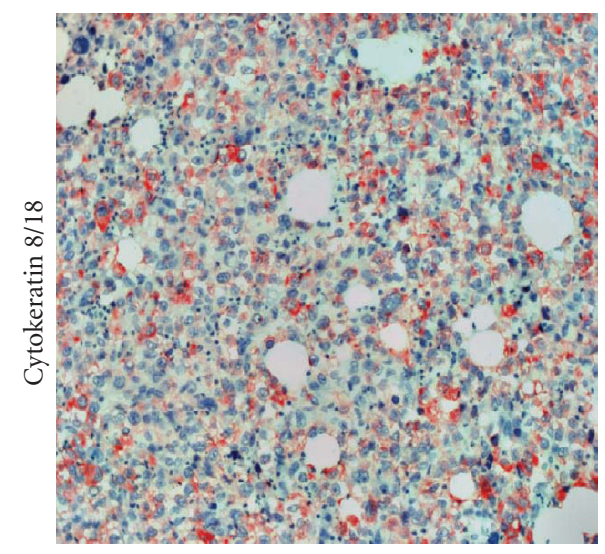

(c)

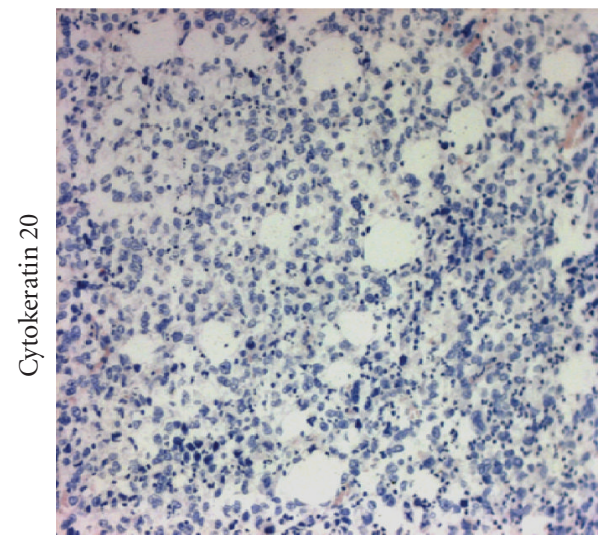

(e)

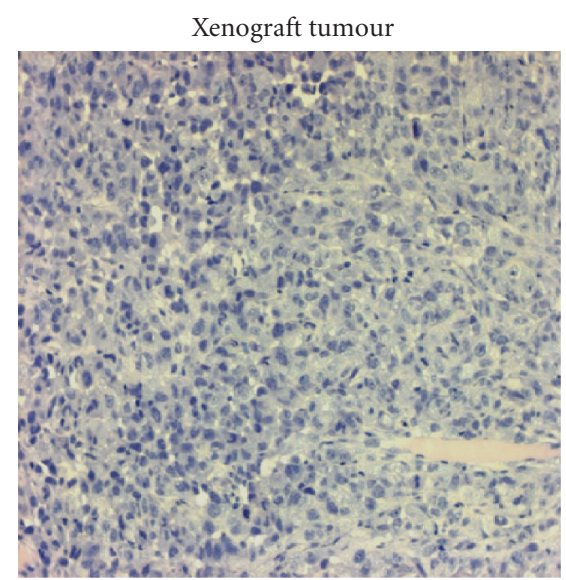

(b)

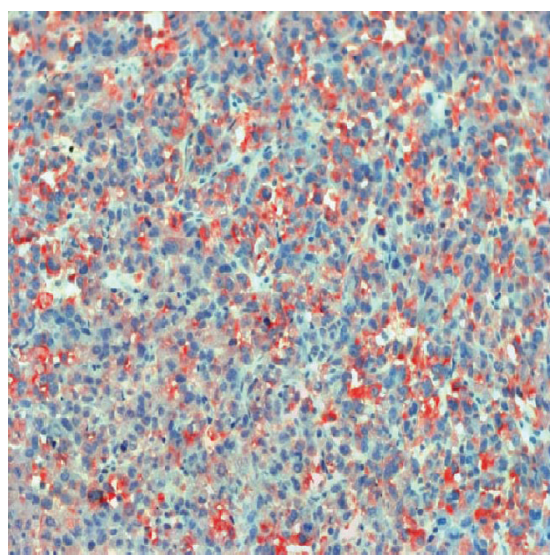

(d)

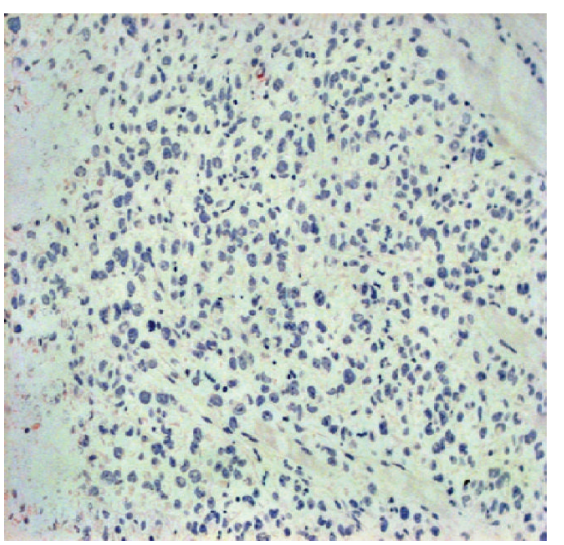

(f)

FIGURE 4: Immunohistochemical analysis of original and corresponding xenograft tumour AKH23. Sections were stained with (a), (b) antibodies specific for CEA, (c), (d) cytokeratin 8/18, and (e), (f) cytokeratin 20. (a) Arrows indicate few stained cells in the original tumour AKH23 reacting with the CEA-specific antibody. Magnification: 200x.

revealed that in most of the corresponding original and xenograft tumour samples expression of oncogenes and genes involved in cell cycle regulation appeared not to be affected by the xenografting process. Major differences within original and xenograft tumour samples as well as their derived cell cultures were detected regarding genes encoding cytokines (IL-8, IL-6) and matrix metalloproteinases (MMP1, MMP-11). This finding can be explained by the fact that these molecules are rather expressed by inflammatory cells (monocytes, neutrophils), stromal fibroblasts, and endothelial cells than by the tumour cells themselves. A high level IL-8 expression, however, was also reported in cultured 
TABLE 5: Relative differences in gene expression levels (n-fold) within tumour samples compared to derived cell cultures. n.d.: not determinable, Ct values obtained with cDNA derived either from cultured cells (\$) or from both tumour samples and cells were below threshold ( $>39$ ).

\begin{tabular}{|c|c|c|c|}
\hline & AKH23 original cells & KFJ9 xenograft cells & KFJ10 xenograft cells \\
\hline BCL2 & $0.37 \pm 0.03$ & $2.60 \pm 0.64$ & $35.13 \pm 7.76$ \\
\hline CCND1 & $0.40 \pm 0.09$ & $0.85 \pm 0.33$ & $0.50 \pm 0.08$ \\
\hline CDC25B & $0.89 \pm 0.14$ & $1.18 \pm 0.11$ & $0.50 \pm 0.08$ \\
\hline CDKN1B & $0.90 \pm 0.17$ & $0.55 \pm 0.11$ & $0.74 \pm 0.13$ \\
\hline CTNNB1 & $0.54 \pm 0.12$ & $0.93 \pm 0.2$ & $1.03 \pm 0.08$ \\
\hline EGFR & $0.46 \pm 0.12$ & $0.36 \pm 0.09$ & $0.78 \pm 0.07$ \\
\hline ERBB2 & $0.73 \pm 0.16$ & $1.24 \pm 0.15$ & $0.68 \pm 0.1$ \\
\hline ETV4 & $0.78 \pm 0.17$ & $0.51 \pm 0.12$ & $1.21 \pm 0.16$ \\
\hline IL6 & n.d.\$ & $0.61 \pm 0.15$ & n.d.\$ \\
\hline IL6R & $5.88 \pm 1.02$ & $4.47 \pm 0.65$ & $2.27 \pm 0.33$ \\
\hline IL8 & $0.54 \pm 0.08$ & $0.89 \pm 0.41$ & $0.92 \pm 0.03$ \\
\hline KRAS2 & $1.08 \pm 0.16$ & $0.50 \pm 0.11$ & $0.73 \pm 0.24$ \\
\hline MET & $0.49 \pm 0.11$ & $0.32 \pm 0.07$ & $0.42 \pm 0.06$ \\
\hline MMP1 & $0.0027 \pm 0.0006$ & n.d. & $1.06 \pm 0.37$ \\
\hline MMP11 & $10.47 \pm 0.99$ & n.d.\$ & $1.41 \pm 0.38$ \\
\hline MYC & $0.87 \pm 0.08$ & $0.53 \pm 0.13$ & $0.37 \pm 0.05$ \\
\hline PTGS2 & $0.71 \pm 0.22$ & n.d. & n.d. \\
\hline SERPINB5 & $0.91 \pm 0.21$ & $0.80 \pm 0.18$ & $0.43 \pm 0.04$ \\
\hline VEGFA & $4.50 \pm 0.92$ & $0.96 \pm 0.17$ & $1.83 \pm 0.21$ \\
\hline VEGFC & n.d.\$ & n.d. & n.d. \\
\hline WNT1 & n.d. & n.d. & n.d. \\
\hline
\end{tabular}

colon carcinoma cells, where it was associated with the metastatic behaviour of these cells [21]. Consistently, we have shown IL-8 expression in cultured xenograft-derived colon carcinoma cells (e.g., KFJ10), and their metastatic potential was demonstrated by colony formation in soft agar assays (data not shown).

Matrix metalloproteinases (MMPs) are a family of extracellular matrix degrading enzymes, which have their physiological role in tissue remodelling processes such as embryonic development or wound healing [22]. In cancer, MMPs are described to be involved in tumour invasion, metastasis, and angiogenesis [23, 24]. MMP-1, also known as interstitial collagenase, is expressed in a wide variety of cells such as stromal fibroblasts, endothelial cells, macrophages, and epithelial cells [25]. Either equal expression levels were found in original and xenograft tumours or expression was exclusively detected in original tumours. A weak or lacking MMP-1 expression in some of the xenograft tumours could not be linked to an individual tumour type. Original tumours representing liver metastases showed higher MMP-1 levels, reflecting the potential of tumour cells to invade and metastasise from their original site to distant organs [26]. Accordingly, AKH23 primary tumour-derived cells exhibiting a markedly high MMP-1 expression level demonstrated a very aggressive growth behaviour when injected into immunodeficient mice. Injection of $5 \times 10^{6}$ cells in this case resulted in growth of tumours of up to $1000 \mathrm{~mm}^{3}$ within 35 days whereas in average xenografted cells took 60 to 80 days to reach this tumour volume (data not shown). MMP-11 in comparison to MMP-1 is described to be specifically expressed in stromal fibroblasts surrounding tumour cells [27]. Thus, the determined reduced expression level of MMP-11 in xenograft tumours most probably is due to the absence of human stroma cells in the murine environment. Interestingly, expression of Cox-2 (PTGS2) and VEGF-C, both known to regulate angiogenesis and lymphangiogenesis, was detected in original tumour samples but, in contrast to VEGF-A, was beyond detection limits in most of the xenograft tissues. Recently, it has been described that these two genes are coexpressed in human colorectal carcinoma cells and can be significantly associated with lymph node metastasis and prognosis [28]. Further investigation of the mechanisms of down regulation of expression of lymphangiogenesis inducing factors in xenografted tumours may give insight into metastatic progression of CRC.

\section{Conclusion}

The developed carefully characterised human xenograft tumours derived from secondary liver tumours share assertive characteristics with their respective original human counterparts. In addition, the established cell cultures offer the possibility to evaluate new therapeutic strategies in vitro before their use in vivo in the corresponding tumour mouse models. These valuable tools might be used for the development and preclinical evaluation of new therapeutic drugs as well as of alternative methods such as expression 
targeted retroviral vectors [29] or liver specific therapeutic nanoparticles [30] generated for an application in cancer gene therapy.

\section{Acknowledgments}

The authors thank Bettina Grasl-Kraupp and Hannes Zwickl, Institute of Cancer Research, Medical University Vienna, and Stefan Stättner, Department of Surgery, Kaiser-FranzJosef-Spital Vienna, for providing primary human liver tumour tissue. They also thank Michaela Wendl and Marielle König-Schuster for taking care of the animals. In addition, they acknowledge the excellent technical assistance of Doris Rosenfellner and the support and technical advice of Ingrid Walter, both at the University of Veterinary Medicine, Institute of Histology and Embryology. The authors also appreciate the help of Irene Sommerfeld-Stur, Institute of Animal Breeding and Genetics, in statistical analysis of the presented data. This work was funded by the Austrian Genome Research Program GEN-AU GZ200.058/6VI/2/2002. The work of M. Stürzl was funded by a grant provided from the Interdisciplinary Center for Clinical Research (IZKF) of the University of Erlangen-Nürnberg.

\section{References}

[1] S. A. Khan, B. R. Davidson, R. Goldin, et al., "Guidelines for the diagnosis and treatment of cholangiocarcinoma: consensus document," Gut, vol. 51, supplement 6, pp. vil-vi9, 2002.

[2] M. Lise, P. Pilati, P. Da Pian, S. Mocellin, D. Nitti, and S. Corazzino, "Treatment options for liver metastases from colorectal cancer," Journal of Experimental \& Clinical Cancer Research, vol. 22, supplement 4, pp. 149-156, 2003.

[3] M. Lise, S. Mocellin, P. Pilati, and D. Nitti, "Colorectal liver metastasis: towards the integration of conventional and molecularly targeted therapeutic approaches," Frontiers in Bioscience, vol. 10, pp. 3042-3057, 2005.

[4] P. Saletti and F. Cavalli, "Metastatic colorectal cancer," Cancer Treatment Reviews, vol. 32, no. 7, pp. 557-571, 2006.

[5] D. A. Tuveson and T. Jacks, "Technologically advanced cancer modeling in mice," Current Opinion in Genetics and Development, vol. 12, no. 1, pp. 105-110, 2002.

[6] D. A. Tuveson, L. Zhu, A. Gopinathan, et al., "Mist1-Kras ${ }^{G 12 D}$ knock-in mice develop mixed differentiation metastatic exocrine pancreatic carcinoma and hepatocellular carcinoma," Cancer Research, vol. 66, no. 1, pp. 242-247, 2006.

[7] M. Kilian, J. I. Gregor, I. Heukamp, et al., "Impact of taurolidin and octreotide on liver metastasis and lipid peroxidation after laparoscopy in chemical induced ductal pancreatic cancer," Investigational New Drugs, vol. 23, no. 2, pp. 157-164, 2005.

[8] V. N. Anisimov, S. V. Ukraintseva, and A. I. Yashin, "Cancer in rodents: does it tell us about cancer in humans?" Nature Reviews Cancer, vol. 5, no. 10, pp. 807-819, 2005.

[9] A. Rangarajan and R. A. Weinberg, "Comparative biology of mouse versus human cells: modelling human cancer in mice," Nature Reviews Cancer, vol. 3, no. 12, pp. 952-959, 2003.

[10] Y. Chen, K.-J. Chang, L.-H. Hwang, C.-N. Chen, and S.H. Tseng, "Establishment and characterization of a rectal cancer model in mice: application to cytokine gene therapy," International Journal of Colorectal Disease, vol. 17, no. 6, pp. 388-395, 2002.
[11] G. D. Paine-Murrieta, C. W. Taylor, R. A. Curtis, et al., "Human tumor models in the severe combined immune deficient (scid) mouse," Cancer Chemotherapy and Pharmacology, vol. 40, no. 3, pp. 209-214, 1997.

[12] F. X. Sun, Z. Y. Tang, K. D. Liu, et al., "Establishment of a metastatic model of human hepatocellular carcinoma in nude mice via orthotopic implantation of histologically intact tissues," International Journal of Cancer, vol. 66, no. 2, pp. 239243, 1996.

[13] X. Y. Fu, J. M. Besterman, A. Monosov, and R. M. Hoffman, "Models of human metastatic colon cancer in nude mice orthotopically constructed by using histologically intact patient specimens," Proceedings of the National Academy of Sciences of the United States of America, vol. 88, no. 20, pp. 9345-9349, 1991.

[14] C. Armengol, G. Tarafa, L. Boix, et al., "Orthotopic implantation of human hepatocellular carcinoma in mice: analysis of tumor progression and establishment of the BCLC-9 cell line," Clinical Cancer Research, vol. 10, no. 6, pp. 2150-2157, 2004.

[15] Y.-S. Gao, X.-P. Chen, K.-Y. Li, and Z.-D. Wu, "Nude mice model of human hepatocellular carcinoma via orthotopic implantation of histologically intact tissue," World Journal of Gastroenterology, vol. 10, no. 21, pp. 3107-3111, 2004.

[16] G. Carlsson, B. Gullberg, and L. Hafström, "Estimation of liver tumor volume using different formulas - an experimental study in rats," Journal of Cancer Research and Clinical Oncology, vol. 105, no. 1, pp. 20-23, 1983.

[17] V. V. Kalinichenko, M. L. Major, X. Wang, et al., "Foxm 1 b transcription factor is essential for development of hepatocellular carcinomas and is negatively regulated by the p19 ${ }^{\mathrm{ARF}}$ tumor suppressor," Genes \& Development, vol. 18, no. 7, pp. 830-850, 2004.

[18] K. J. Livak and T. D. Schmittgen, "Analysis of relative gene expression data using real-time quantitative PCR and the $2^{-\Delta \Delta C}$ T method," Methods, vol. 25, no. 4, pp. 402-408, 2001.

[19] S. Hammarström, "The carcinoembryonic antigen (CEA) family: structures, suggested functions and expression in normal and malignant tissues," Seminars in Cancer Biology, vol. 9, no. 2, pp. 67-81, 1999.

[20] P. G. Chu and L. M. Weiss, "Keratin expression in human tissues and neoplasms," Histopathology, vol. 40, no. 5, pp. 403439, 2002.

[21] A. Li, M. L. Varney, and R. K. Singh, "Expression of interleukin 8 and its receptors in human colon carcinoma cells with different metastatic potentials," Clinical Cancer Research, vol. 7, no. 10, pp. 3298-3304, 2001.

[22] T. H. Vu and Z. Werb, "Matrix metalloproteinases: effectors of development and normal physiology," Genes \& Development, vol. 14, no. 17, pp. 2123-2133, 2000.

[23] W. G. Stetler-Stevenson, "Matrix metalloproteinases in angiogenesis: a moving target for therapeutic intervention," The Journal of Clinical Investigation, vol. 103, no. 9, pp. 1237-1241, 1999.

[24] M. Egeblad and Z. Werb, "New functions for the matrix metalloproteinases in cancer progression," Nature Reviews Cancer, vol. 2, no. 3, pp. 161-174, 2002.

[25] C. E. Brinckerhoff, J. L. Rutter, and U. Benbow, "Interstitial collagenases as markers of tumor progression," Clinical Cancer Research, vol. 6, no. 12, pp. 4823-4830, 2000.

[26] U. Benbow, M. P. Schoenermark, T. I. Mitchell, et al., "A novel host/tumor cell interaction activates matrix metalloproteinase I and mediates invasion through type I collagen," The Journal of Biological Chemistry, vol. 274, no. 36, pp. 25371-25378, 1999. 
[27] P. Bassed, J. P. Bellocq, C. Wolf, et al., "A novel metalloproteinase gene specifically expressed in stromal cells of breast carcinomas," Nature, vol. 348, no. 6303, pp. 699-704, 1990.

[28] L. T. Soumaoro, H. Uetake, Y. Takagi, et al., "Coexpression of VEGF-C and Cox-2 in human colorectal cancer and its association with lymph node metastasis," Diseases of the Colon \& Rectum, vol. 49, no. 3, pp. 392-398, 2006.

[29] C. Metzl, D. Mischek, B. Salmons, W. H. Günzburg, M. Renner, and D. Portsmouth, "Tissue- and tumor-specific targeting of murine leukemia virus-based replication-competent retroviral vectors," Journal of Virology, vol. 80, no. 14, pp. 7070-7078, 2006.

[30] Y. Iwasaki, M. Ueda, T. Yamada, et al., "Gene therapy of liver tumors with human liver-specific nanoparticles," Cancer Gene Therapy, vol. 14, no. 1, pp. 74-81, 2007. 

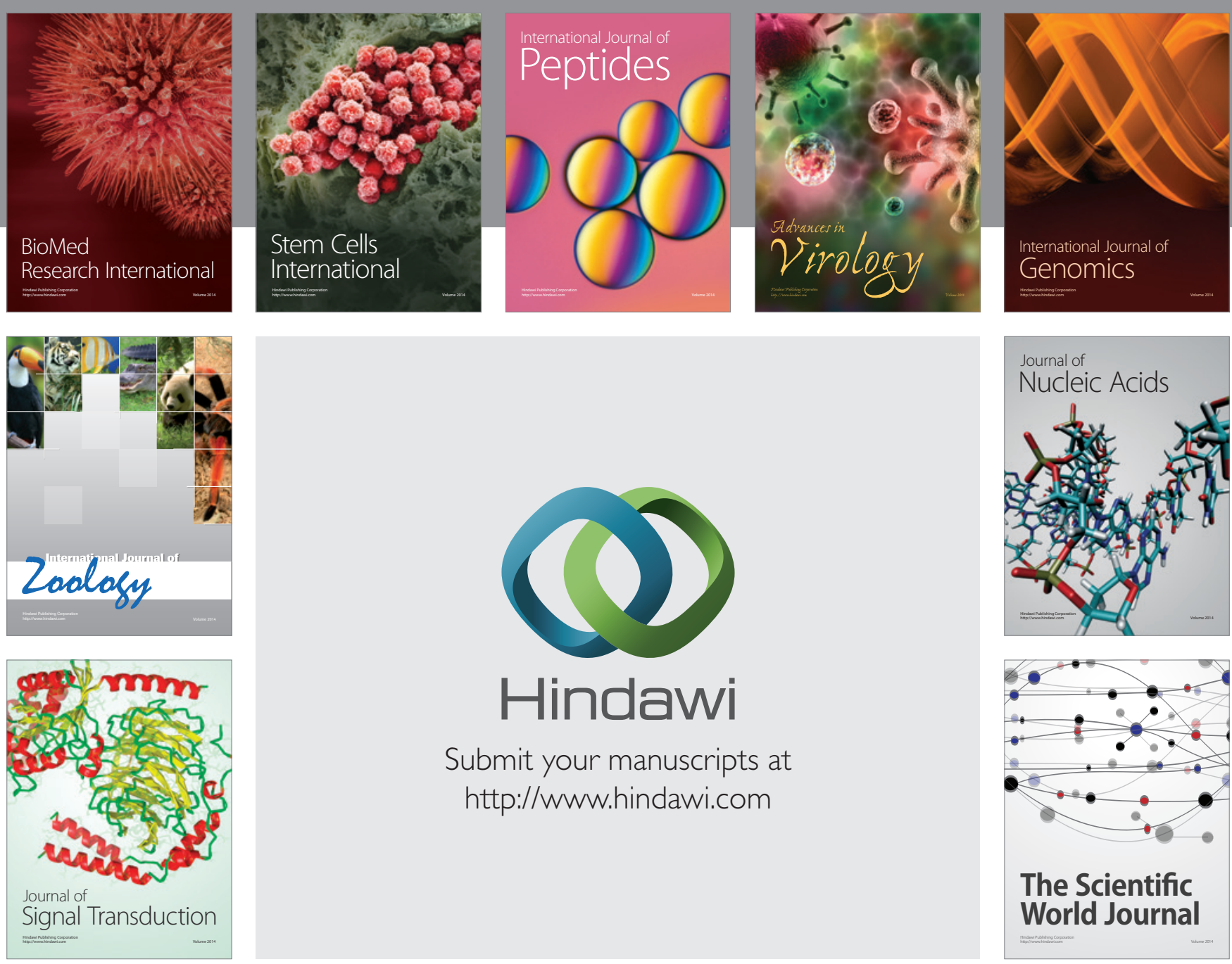

Submit your manuscripts at

http://www.hindawi.com
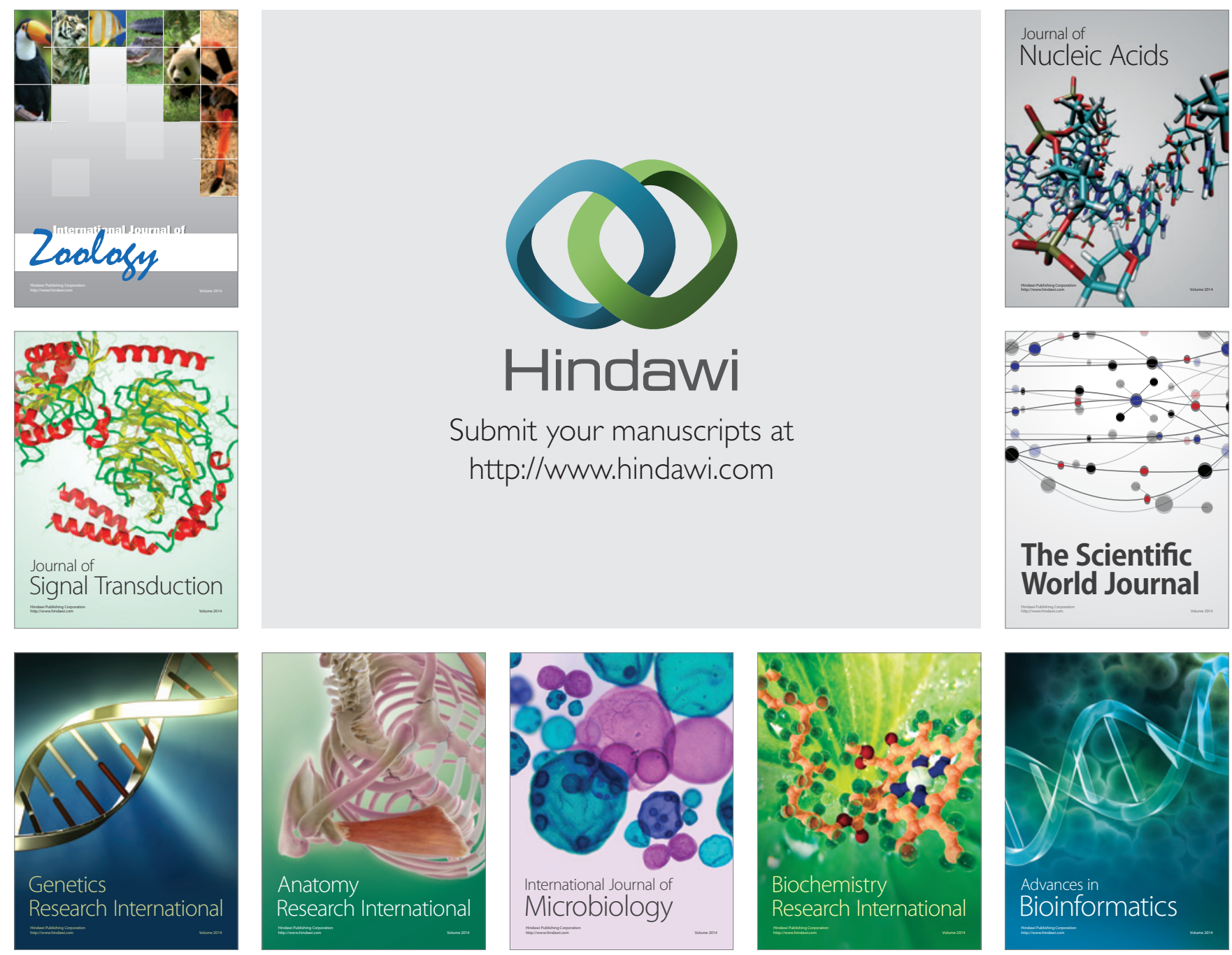

The Scientific World Journal
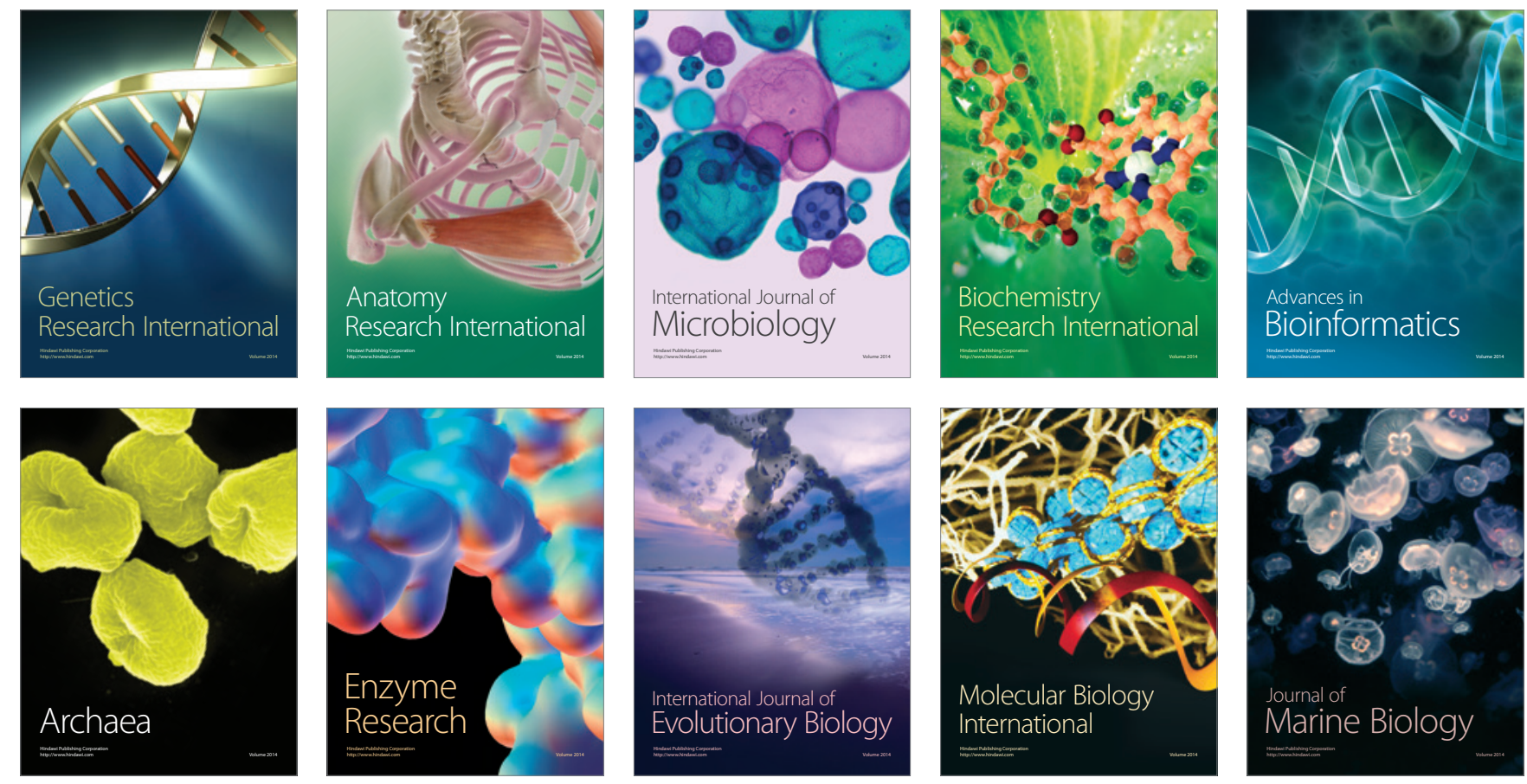